\title{
The Luminescence of Potassium Siliconiobates
}

\author{
G. BLASSE
}

Physical Laboratory, State University of Utrecht, P.O. Box 80.000, 3508 TA Utrecht, The Netherlands

AND B. RAVEAU

Laboratoire de Cristallographie et Chimie du Solide associé au CNRS No. 251, Université de Caen, Esplanade de la Paix, 14032 Caen Cedex, France

Received December 5, 1978

\begin{abstract}
The luminescence of $\mathrm{K}_{6} \mathrm{Nb}_{6} \mathrm{Si}_{4} \mathrm{O}_{26}$ and $\mathrm{K}_{8} \mathrm{Nb}_{14} \mathrm{Si}_{4} \mathrm{O}_{47}$ is reported. Three emission bands have been observed, each with its own excitation band. In the case of $\mathrm{K}_{8} \mathrm{Nb}_{14} \mathrm{Si}_{4} \mathrm{O}_{47}$ these emissions can be ascribed to the three crystallographically different niobate octahedra. The emission from the edge-sharing octahedron is exceptional, because the Stokes shift is small and the thermal quenching temperature relatively high. In the case of $\mathrm{K}_{6} \mathrm{Nb}_{6} \mathrm{Si}_{4} \mathrm{O}_{26}$ we are forced to accept the presence of stacking faults in order to explain all the emission bands.
\end{abstract}

\section{Introduction}

Oxides containing highly charged cations (e.g., silicates, phosphates) are usually very suitable as host lattices for luminescent ions (see, e.g., Ref. (1)). Because of the stiffness of these lattices the luminescent centers cannot change their equilibrium distance drastically after excitation. It is well known that small changes in this distance imply high thermal quenching temperatures of the luminescence and high luminescence quantum efficiencies.

Over a couple of years one of the authors studied extensively the luminescence of the octahedral niobate group $\left(\mathrm{NbO}_{6}{ }^{7-}\right)(2-5)$ and found a number of relations between crystal structure and niobate luminescence.

The other author prepared several siliconiobates and determined their crystal structure $(6-9)$. In view of what has been said before, it seemed interesting to investigate the luminescence of siliconiobates. This paper reports such a study. On the one hand we have found exceptional luminescent behavior for certain niobate octahedra in the siliconiobates; on the other we can show that luminescence is a useful technique in discovering deviations from the ideal crystal structure.

\section{Experimental}

The preparation of the samples has been described before $(6-8)$. The optical measurements were performed as described previously (10).

\section{Results}

At first sight our results were rather disappointing because none of the materials investigated showed luminescence at room temperature and some of them not even at liquid nitrogen temperature. Because $\mathrm{K}_{6} \mathrm{Nb}_{6} \mathrm{Si}_{4} \mathrm{O}_{26}$ showed the strongest emission at the latter temperature, it was investigated 
in more detail and at liquid helium temperature.

Excitation into the optical band edge (in the 270 - to 280 -nm region) yields an emission band with reasonable efficiency and peaking at $480 \mathrm{~nm}$. Excitation at lower energies results in another emission band peaking at $425 \mathrm{~nm}$. Excitation into the tail of the absorption edge $(-340 \mathrm{~nm})$ gives a very weak emission band peaking at about $520 \mathrm{~nm}$. These features become clear from the excitation spectra given in Fig. 1. The 425-nm emission band has an excitation band with a maximum at $315 \mathrm{~nm}$, the 480 $\mathrm{nm}$ emission band has an excitation band at $275 \mathrm{~nm}$, and the $520-\mathrm{nm}$ emission band has an excitation band at about $330 \mathrm{~nm}$.

At liquid nitrogen temperature this behavior is also observed, but the 520-nm emission band is hardly detectable and the intensity of the $275-\mathrm{nm}$ excitation band has grown relative to that of the 315-nm excitation band. At about $125^{\circ} \mathrm{K}$ the $425-\mathrm{nm}$ and at about $225^{\circ} \mathrm{K}$ the $480-\mathrm{nm}$ emission bands have disappeared. In agreement with these data the diffuse reflection spectrum of $\mathrm{K}_{6} \mathrm{Nb}_{6} \mathrm{Si}_{4} \mathrm{O}_{26}$ at room temperature shows the onset of absorption at about $380 \mathrm{~nm}$. The absorption coefficient increases up to some $290 \mathrm{~nm}$ where it reaches its maximum value.

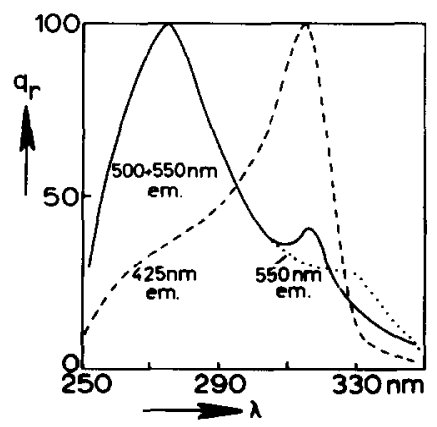

FIG. 1. Relative excitation spectra of the luminescence of $\mathrm{K}_{6} \mathrm{Nb}_{6} \mathrm{Si}_{4} \mathrm{O}_{26}$ at liquid helium temperature. $q_{r}$ gives the relative quantum output. Solid line, 500-nm emission; dotted line, 550-nm emission; broken line, 425-nm emission.
In the case of $\mathrm{K}_{8} \mathrm{Nb}_{14} \mathrm{Si}_{4} \mathrm{O}_{47}$ the band system with $425-\mathrm{nm}$ emission and $315-\mathrm{nm}$ excitation maximum dominates. The two other band systems are present, but they are much weaker than in $\mathrm{K}_{6} \mathrm{Nb}_{6} \mathrm{Si}_{4} \mathrm{O}_{26}$. The reflection spectrum of $\mathrm{K}_{8} \mathrm{Nb}_{14} \mathrm{Si}_{4} \mathrm{O}_{47}$ shows the onset of absorption at $380 \mathrm{~nm}$ also. The absorption increases strongly up to $340 \mathrm{~nm}$ and reaches another absorption maximum at about $290 \mathrm{~nm}$.

\section{Discussion}

The crystal structure of $\mathrm{K}_{6} \mathrm{Nb}_{6} \mathrm{Si}_{4} \mathrm{O}_{26}$ contains only one crystallographical site for the niobium ion (6). It seems obvious to assume that the excitation band at $275 \mathrm{~nm}$ corresponds to optical absorption by these (intrinsic) niobate groups, because this wavelength is near the absorption maximum in the reflection spectrum. This is the behavior we observed previously for many other niobates (2-5). The corresponding emission band at $480 \mathrm{~nm}$ shows a normal Stokes shift, viz., about $16 \mathrm{kK}(1 \mathrm{kK}=$ $\left.1000 \mathrm{~cm}^{-1}\right)$. In our earlier studies we observed typically Stokes shifts of some $15 \mathrm{kK}$ $(2,3)$. We also derived a relation between the position of the absorption edge or the excitation band maximum and the thermal quenching temperature of the luminescence (2). This relation predicts for the thermal quenching temperature $250-300^{\circ} \mathrm{K}$, if the excitation band is at $275 \mathrm{~nm}$. In view of the complicated system we are working with, the agreement with the experimental value $\left(225^{\circ} \mathrm{K}\right)$ is satisfying. We may conclude, therefore, that the intrinsic niobate group in $\mathrm{K}_{6} \mathrm{Nb}_{6} \mathrm{Si}_{4} \mathrm{O}_{26}$ behaves normally as far as its luminescence is concerned. There is no special influence of the silicate groups. This may be due to the fact that the niobate octahedra are neighbored only on one side by silicon ions.

The relation mentioned before predicts also the absence of any luminescence, if the excitation band is at wavelengths longer than 
$300 \mathrm{~nm}$. It is here that the siliconiobates become exceptional. The emission peaking at $425 \mathrm{~nm}$ with its excitation maximum at $315 \mathrm{~nm}$ is a very clear exception to this rule. Note also that its Stokes shift is extremely small, viz., $9 \mathrm{kK}$. The band system at even longer wavelengths is also exceptional, but it is not very intense. Further these emissions are remarkable because the crystal structure has only one crystallographic site for niobium. As a consequence these emissions must originate from "defect" niobate groups. This follows also from the fact that their luminescence is excited in the long tail at the long-wavelength side of the optical band edge.

From crystal-chemical considerations and from the results of the luminescence measurements the most obvious possibility is the existence of a stacking fault changing slightly the composition in such a way that layers of composition " $\mathrm{Nb}_{8} \mathrm{O}_{21}$ " are formed. In these layers the niobate octahedra share edges and corners. The crystal structure of $\mathrm{K}_{8} \mathrm{Nb}_{14} \mathrm{Si}_{4} \mathrm{O}_{47}(17)$ consists of layers of this type together with layers with composition " $\mathrm{Nb}_{6} \mathrm{Si}_{4} \mathrm{O}_{26}$ ": $\mathrm{K}_{2} \mathrm{Nb}_{8} \mathrm{O}_{21}+\mathrm{K}_{6} \mathrm{Nb}_{6} \mathrm{Si}_{4} \mathrm{O}_{26}$ (see Fig. 2).

The additional layer contains rings of six edge-sharing niobate octahedra. These rings

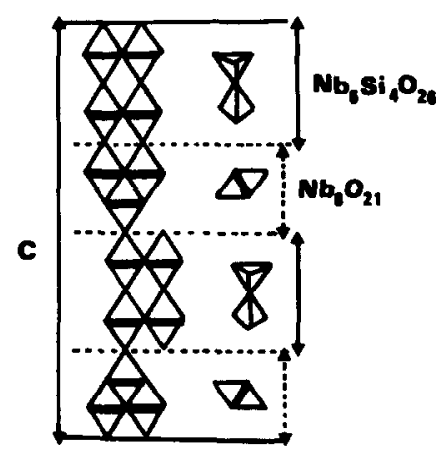

FIG. 2. Schematic representation of the crystal structure of $\mathrm{K}_{8} \mathrm{Nb}_{14} \mathrm{Si}_{4} \mathrm{O}_{47}$ : stacking of the " $\mathrm{Nb}_{6} \mathrm{Si}_{4} \mathrm{O}_{26}$ " and " $\mathrm{Nb}_{8} \mathrm{O}_{21}$ " layers along $c$. Only the niobate octahedra and the pyrosilicate group have been given. Compare also Refs. (7) and (8). are connected by other niobate octahedra via corner sharing. There are three times more octahedra in the rings than octahedra connecting the rings. In view of the intensity data we ascribe the emission at $425 \mathrm{~nm}$ (with excitation at $315 \mathrm{~nm}$ ) to the octahedra in the ring and the emission at $520 \mathrm{~nm}$ to the octahedra between the rings. It has been shown before (3) that edge-sharing niobate octahedra are usually efficient luminescent centers. This is especially true in the present compound in view of the position of the excitation band. It is clear that the presence of luminescence is due to the small Stokes shift of the emission from these groups.

These niobate groups are strongly distorted (11). This is probably due to the fact that so many octahedra are stacked together in the edge-sharing region. The ring octahedra contain one very short $\mathrm{Nb}-\mathrm{O}$ distance. In $\mathrm{Ba}_{6+x} \mathrm{Nb}_{14} \mathrm{Si}_{4} \mathrm{O}_{47}(x \cong 0.23)$ with the same structure as $\mathrm{K}_{8} \mathrm{Nb}_{14} \mathrm{Si}_{4} \mathrm{O}_{47}$ this distance has been determined to be $1.84 \AA$, whereas the average value of the six $\mathrm{Nb}-\mathrm{O}$ distances is $2.00 \AA(11)$. As argued before the lowest charge-transfer transition occurs mainly in this very short distance (12). But it is this oxygen ion $(\mathrm{O}(1))$ which finds a highly charged cation, viz., another $\mathrm{Nb}^{5+}$ ion, behind itself. This, as argued above, is a condition for small expansion after excitation resulting in a small Stokes shift and an unexpected occurrence of luminescence.

The weak luminescence peaking at $520 \mathrm{~nm}$ could not be studied with any accuracy. Probably the relevant octahedra are fixed closely in between the rings of edge-sharing octahedra resulting in a relatively high quenching temperature of the luminescence.

As far as $\mathrm{K}_{6} \mathrm{Nb}_{6} \mathrm{Si}_{4} \mathrm{O}_{26}$ is concerned, we conlude that the luminescence measurements reveal the presence of small deviations from the ideal composition, viz., $\left(\mathrm{K}_{6} \mathrm{Nb}_{6} \mathrm{Si}_{4} \mathrm{O}_{26}\right)_{n} \cdot \mathrm{K}_{2} \mathrm{Nb}_{8} \mathrm{O}_{21}$, where $n$ is very large. These measurements are very sensitive, because the luminescence of the 
" $\mathrm{Nb}_{8} \mathrm{O}_{21}$ " layer can be excited in a region where the pure compound does not absorb.

Let us now turn to $\mathrm{K}_{8} \mathrm{Nb}_{14} \mathrm{Si}_{4} \mathrm{O}_{47}$ (i.e., $\mathrm{K}_{6 n+2} \cdot\left(\mathrm{Nb}_{6} \mathrm{Si}_{4} \mathrm{O}_{26}\right)_{n} \cdot \mathrm{Nb}_{8} \mathrm{O}_{21}$ with $\left.n=1\right)$ (7). This means that the niobate groups, which in $\mathrm{K}_{6} \mathrm{Nb}_{6} \mathrm{Si}_{4} \mathrm{O}_{26}$ are responsible for the defect niobate luminescence, form now an essential part of the crystal structure. In fact the absorptions corresponding to the 315 and 330-nm excitation band have become orders of magnitude stronger, although the niobate octahedra with the $275-\mathrm{nm}$ excitation band are still observable in the reflection spectrum. The results of the luminescence measurements on $\mathrm{K}_{8} \mathrm{Nb}_{14} \mathrm{Si}_{4} \mathrm{O}_{47}$ confirm the model proposed for the luminescence of $\mathrm{K}_{6} \mathrm{Nb}_{6} \mathrm{Si}_{4} \mathrm{O}_{26}$. The 425-nm emission dominates. The $480-\mathrm{nm}$ emission can just be seen as a shoulder upon 275-nm excitation. The 480-nm emission cannot be excited solely, because the large amount of $425-\mathrm{nm}$ emitting octahedra absorb the $275-\mathrm{nm}$ excitation also.

\section{Acknowledgments}

The authors are indebted to Mrs. G. P. M. van den Heuvel and G. J. Dirksen for the performance of the optical measurements.

\section{References}

1. G. Blasse, J. Chem. Phys. 51, 3529 (1969).

2. G. BLASSE, J. Chem. Phys. 48, 3108 (1968).

3. G. BLASSE AND A. BRIL, Z. Phys. Chem. N. F.57, 187 (1968).

4. G. Blasse AND A. BRIL, J. Solid State Chem. 3,69 (1971).

5. G. BLASSE, 'Phys. Status Solidi A 20, K99 (1973).

6. J. CHOISNET, N. NGUYEN, D. GROULT, AND B. RAVEAU, Mater. Res. Bull. 11, 887 (1976).

7. J. Choisnet, N. NGuYen, and B. Raveau, Mater. Res. Bull. 12, 92 (1977).

8. N. Nguyen, F. Studer, D. Groult, J. ChotsNet, and B. Raveau, J. Solid State Chem. 19, 369 (1976).

9. F. Studer and B. Raveau, Phys. Status Solidi A 48, 301 (1978); 49, 189 (1978).

10. J. TH. W. DE HAIR AND G. BLASSE, J. Lumin. 14, 307 (1976).

11. D. M. Evans AND L. KATZ, J. Solid State Chem. 8, 150 (1973).

12. G. BLASSE AND G. P. M. VAN DEN HeUVEL, $J$. Solid State Chem. 10, 206 (1974); G. BLASSE, J. Inorg. Nucl. Chem., 41, 639 (1979). 